\title{
Evolution of real area of contact due to combined normal load and sub-surface straining in sheet metal
}

\author{
Meghshyam SHISODE ${ }^{1, *}$, Javad HAZRATI ${ }^{1}$, Tanmaya MISHRA ${ }^{2}$, Matthijn DE ROOIJ ${ }^{2}$, Ton VAN DEN BOOGAARD ${ }^{1}$ \\ ${ }^{1}$ Nonlinear Solid Mechanics, Faculty of Engineering Technology, University of Twente, Enschede 7522 NB, The Netherlands \\ ${ }^{2}$ Surface Technology and Tribology, Faculty of Engineering Technology, University of Twente, Enschede 7522 NB, The Netherlands \\ Received: 12 April 2020 / Revised: 10 July 2020 / Accepted: 18 August 2020 \\ (C) The author(s) 2020 .
}

\begin{abstract}
Understanding asperity flattening is vital for a reliable macro-scale modeling of friction and wear. In sheet metal forming processes, sheet surface asperities are deformed due to contact forces between the tools and the workpiece. In addition, as the sheet metal is strained while retaining the normal load, the asperity deformation increases significantly. Deformation of the asperities determines the real area of contact which influences the friction and wear at the tool-sheet metal contact. The real area of contact between two contacting rough surfaces depends on type of loading, material behavior, and topography of the contacting surfaces. In this study, an experimental setup is developed to investigate the effect of a combined normal load and sub-surface strain on real area of contact. Uncoated and zinc coated steel sheets (GI) with different coating thicknesses, surface topographies, and substrate materials are used in the experimental study. Finite element (FE) analyses are performed on measured surface profiles to further analyze the behavior observed in the experiments and to understand the effect of surface topography, and coating thickness on the evolution of the real area of contact. Finally, an analytical model is presented to determine the real area contact under combined normal load and sub-surface strain. The results show that accounting for combined normal load and sub-surface straining effects is necessary for accurate predictions of the real area of contact.
\end{abstract}

Keywords: asperity flattening; real area of contact; sub-surface strain; zinc coating; sheet metal forming

\section{Introduction}

Evolution of sheet surface topography due to asperity flattening is one of the key parameters to predict friction and wear at the tool-workpiece interface. For example, friction models proposed by Bay [1,2] and Wanheim et al. [3] include real area of contact as an important parameter. The real area of contact is much lower than the nominal contact area at the tool-workpiece interface. Therefore, the local contact pressure developed at the asperity level is much higher than the nominal pressure and yield strength of the material, which may plastically deform the asperities. The real area of contact for a given loading condition or a combination of loads is generally determined either by dedicated experiments or physics based models. There are numerous models and experimental studies available for normal load flattening for uncoated [4-6] and coated sheets [7-11]. In a typical sheet metal forming process, the sheet surface is deformed due to a contact pressure (normal load), sub-surface strain in the sheet metal, and sliding of the tool over the sheet surface. A combination of these factors at the tool-workpiece contact interface influences the real area of contact. When straining is present, asperity flattening or roughening may occur. In the case of free surface straining, surface roughening is more likely to happen which can be explained by grain rotations $[12,13]$. On

* Corresponding author: Meghshyam SHISODE, E-mail: m.p.shisode@utwente.nl 
the contrary, a normal load combined with sub-surface strain substantially increases the asperity flattening and real area of contact as confirmed by several experimental studies [6, 14-18]. In this case, plastic deformation of the bulk material reduces the effective hardness leading to easier asperity deformation.

Wilson and Sheu [17] performed rolling experiments on aluminum alloy specimens which exhibit combined normal load and sub-surface straining condition. Specimens with triangular shaped asperities oriented parallel to the rolling direction were used. The width of the flattened asperity crests was measured on the deformed specimens to determine the real area of contact. Sutcliffe [16] performed bi-axial experiments with combined normal contact loads and bulk tensile strain on copper specimens with triangular ridges aligned transversely to the bulk strain direction. Nielsen et al. [15] performed a similar experiments on aluminum alloy specimens. The results from these experimental studies on different materials show that the real area of contact increases monotonically and reaches the nominal area asymptotically with increasing strain. All these studies provide good insights on the effect of subsurface straining. However, the experiments are limited to specimens with uniformly spaced and ideal shaped asperities which are far from the realistic engineering surfaces. Westeneng [6] performed similar experiments on aluminum specimens with arbitrary shaped asperities under combined normal load and longitudinal sub-surface strain. The results show a similar trend as that of specimens with ideal shaped asperities. So far, the experimental studies are limited to uncoated sheets. Nowadays, zinc coated (GI) sheets textured by electro discharged textured (EDT) rolls are widely used in deep drawing applications due to its corrosion resistance, stable tribological behavior, and better paint appearance. Hence, it is important to characterize the behavior of textured coated sheets.

Modeling the combined effect of normal load and sub-surface strain on asperity deformation is complex. Simplified 2-dimensional (2D) models have been proposed in the past. For instance, Wilson and Sheu [17] and Sutcliffe [16] proposed models for ideal surfaces with uniform asperities oriented in parallel or perpendicular to the straining direction. They validated the models using dedicated experiments on ideal surfaces as mentioned above. However, the quantitative com- parison of the model results and experiments showed that the model underestimates the real area of contact. Sutcliffe [16] used a slip-line analysis in a plane strain situation to predict asperity deformation. However, these 2D models are too simplified to accurately describe the surface deformation of the engineering surfaces. Westeneng [6] adopted these models to derive a model for arbitrary shaped asperities and height distribution assuming an ideal plastic material behavior. The model requires a calibration parameter which can be determined either by FE simulations or experiments.

The aim of this paper is to investigate the evolution of surface topography and more specifically the real area of contact under combined normal load and sub-surface strain for uncoated and coated sheets. Combined normal load and sub-surface strain experiments are performed on samples of different surface topographies, coating thicknesses, and substrate materials. Furthermore, Westeneng's [6] model is adopted to describe the surface deformation and to predict the real area of contact under specific combination of normal load and sub-surface strain. The required model parameters are determined using the experimental results.

The paper is organized as follows. In Section 2, experiments to investigate the effect of combined normal load and sub-surface strain on real area of contact are presented. In Section 3, plane strain FE simulations performed to investigate the effect of different parameters on the real area of contact are described. In Section 4, the modeling strategy to predict the real area of contact is presented followed by discussion and conclusions.

\section{Combined normal load and sub-surface strain experiments}

\subsection{Experimental setup}

To mimic the sheet metal surface deformation during forming processes, a normal load setup developed by Shisode et al. [11] is adopted to perform the combined normal load and sub-surface strain experiments. The setup allows application of a constant nominal pressure on the sheet surface while the material is deformed in uniaxial tension. Figure 1(a) shows the setup and the sample geometry. Figure 1(b) shows the assembly of 


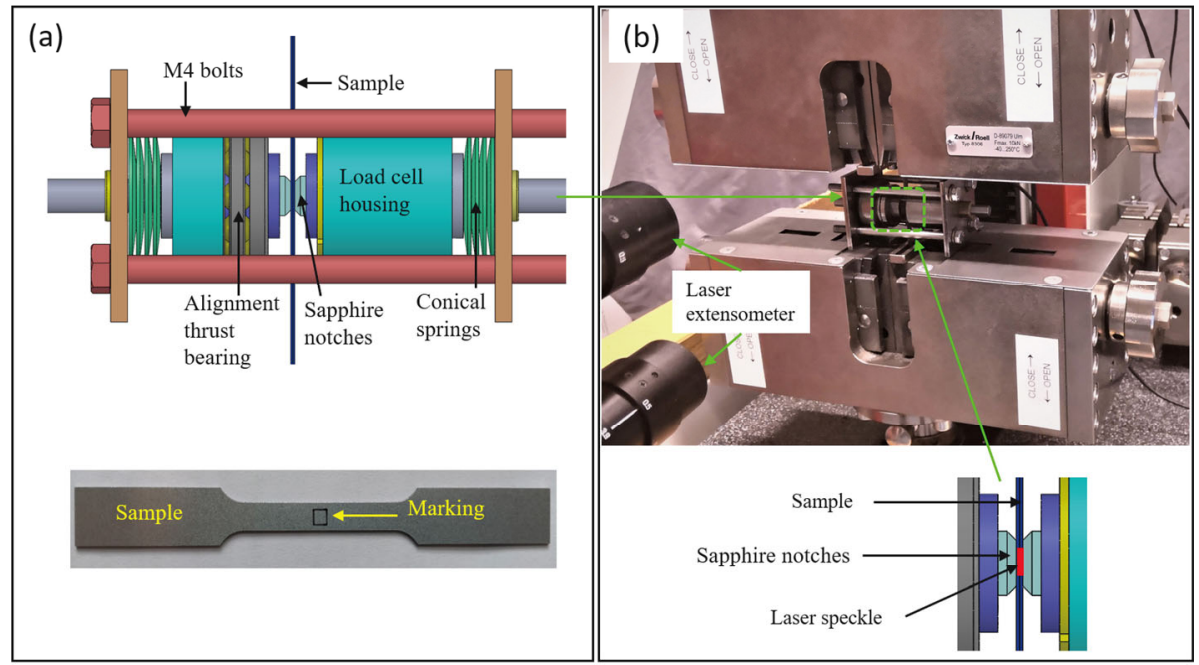

(c)

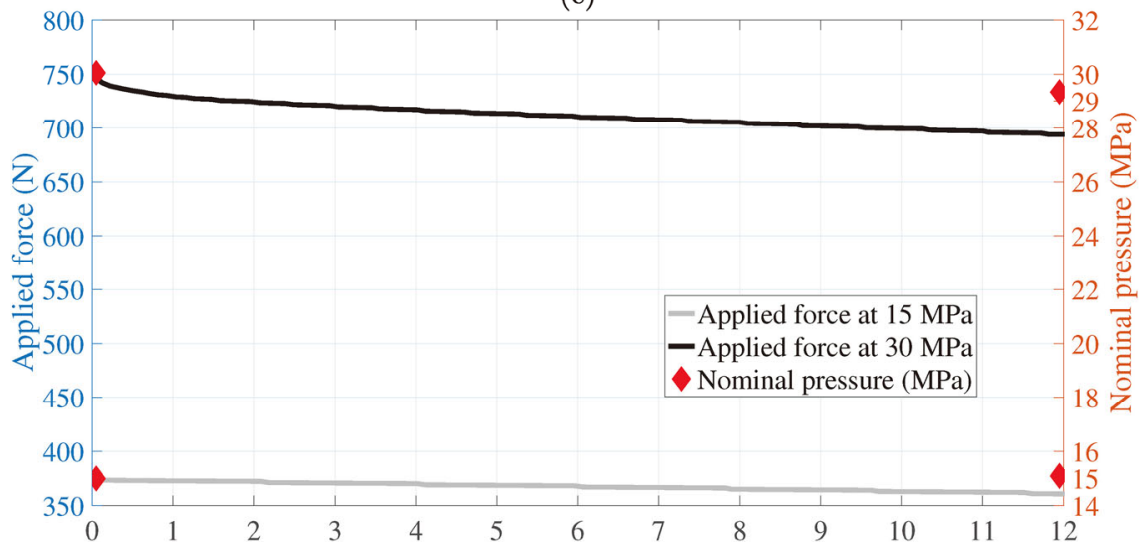

Fig. 1 Experimental setup. (a) Combined normal load and strain unit, sample geometry, (b) test setup, and (c) evolution of normal force and nominal pressure vs. uniaxial strain (sample 1).

the setup on a tensile tester for combined normal load and uniaxial tensile strain experiments. The main components of the setup are polished sapphire notches for normal loading, load cell ( $2 \mathrm{kN})$, thrust bearing for alignment, M4 clamping bolts and Belleville washers also known as conical springs. A sheet sample of geometry same as a typical tensile test is loaded at the center for a required nominal pressure. Please refer [11] for more details on the normal loading of the sample. The longer side of the sapphire notches with rectangular contact area $(5 \mathrm{~mm} \times 7 \mathrm{~mm})$ covers full width of the sample $(5 \mathrm{~mm})$ at the center. The sapphire notches are highly polished with a surface roughness below $1 \mathrm{~nm}$. It helps to minimize the effect of notch asperities ploughing through the sheet surface during straining which can influence the real area of contact. To make the interpretation of the results easier, a constant nominal pressure is maintained on the surface of the specimen during the deformation. However, this might be affected during tensile straining of the sample because of the thickness and width reduction in the deformation zone. The decrease in thickness reduces the nominal pressure due to loss of clamping load at the notches. On the contrary, reduction in sample width increases the nominal pressure on the sample. To nullify these effects, a stack of conical springs is used to maintain a constant nominal pressure on the surface of the specimen. A design study is performed to determine the number of springs in stack and their specifications. Reductions in width and thickness at a given longitudinal strain for each sample are determined using their plastic strain ratio (Lankford coefficients). Furthermore, the loss in clamping load for the stack of springs is determined 
using the force vs. deflection curve of the spring. Finally, the stack of springs is optimized such that the percentage loss in clamping force and nominal contact areas are equal to ensure a constant nominal pressure. Figure 1(c) shows an example of measured normal load by a load cell as the sample is strained. The initial and final nominal pressures determined from the measured normal load and nominal area are also plotted. The results show that the loss in nominal pressure is less than $1 \mathrm{MPa}$.

\subsection{Sheet samples and test procedure}

Zinc coated (GI) and uncoated steel samples which are used in the normal load flattening study [11] are used for the combined normal load and sub-surface strain experiments to investigate the influence of coating thicknesses and surface topography. Table 1 shows the sample details and Fig. 2 shows the surface topographies of all samples. The sample numbers 1 through 4 in Fig. 2 refer to samples prepared from four different sheets as in Table 1. Samples 1 and 2 have similar surface topography with peaks separated by much lower spacing compared to sample $3\left(R_{\mathrm{sm}}\right.$ in Table 1). All the samples are textured by electrical discharged textured (EDT) rolls.

The test samples are prepared with a total length of $100 \mathrm{~mm}$, gauge length of $30 \mathrm{~mm}$, and width of $5 \mathrm{~mm}$ at the center. A square mark of $2.5 \mathrm{~mm} \times 2.5 \mathrm{~mm}$ is made
Table 1 Samples used in the experiments.

\begin{tabular}{ccccc}
\hline Sample & $\begin{array}{c}\text { Material } \\
{[11]}\end{array}$ & $\begin{array}{c}\text { Coating } \\
\text { thickness } \\
(\mu \mathrm{m})[11]\end{array}$ & $\begin{array}{c}\text { Roughness, } \\
S_{a}(\mu \mathrm{m}) \\
{[11]}\end{array}$ & $\begin{array}{c}\text { Mean peak } \\
\text { spacing, } \\
R_{\mathrm{sm}}(\mu \mathrm{m})\end{array}$ \\
\hline 1 & DX56(GI) & 7 & 1.1 & 66 \\
2 & DX56(GI) & 14 & 1.6 & 76 \\
3 & S220 (GI) & 23 & 1.0 & 153 \\
4 & $\begin{array}{c}\text { DC04 } \\
\text { (uncoated) }\end{array}$ & - & 1.3 & 95 \\
\hline
\end{tabular}

on the sample (Fig. 1(a)) where the surface height measurements are performed before and after the experiment to determine the real area of contact using a confocal microscopy. A sample is inserted between the loading notches making sure that the marked area is completely covered by the notches. The required normal load is applied using four M4 bolts to reach the desired nominal pressure. Once the required nominal pressure is reached, the setup is mounted on the tensile test machine for uniaxial tensile deformation.

During straining, the setup moves along with the sample which helps to reduce the sliding effects between the sample and the sapphire notches. This also ensures that the same clamping area is subjected to normal load during straining. In addition, the surface of the samples is wetted with a small amount of Fuchs Anticorit PLS100T lubricant to further reduce the friction and the sliding effects between the sample and the
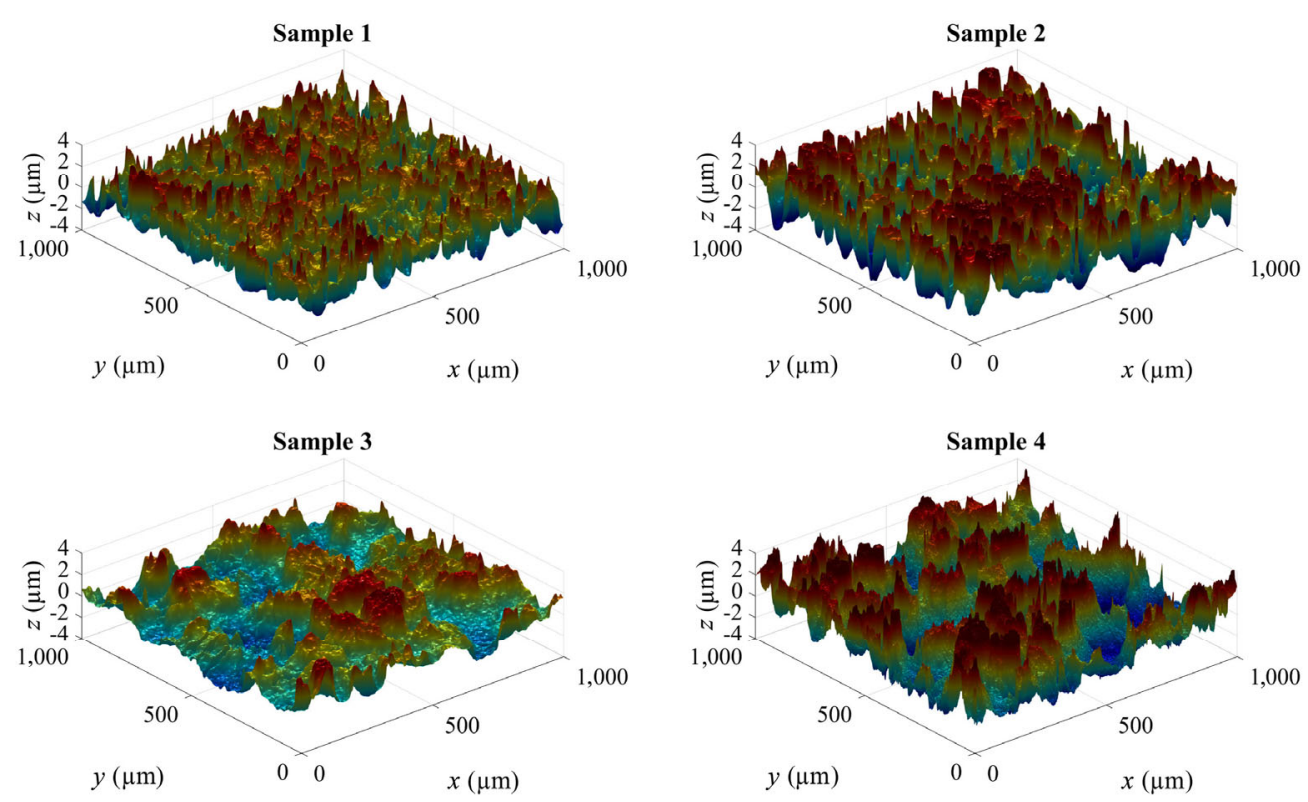

Fig. 2 Height data of undeformed samples showing different surface textures. 
sapphire notches. It can be safely assumed that the lubricant amount is not enough to completely fill the rough surface valleys. Therefore, no hydrostatic or lubricant squeeze effects are expected. Longitudinal strain is measured using a laser extensometer (Fig. 1(b)). For this purpose, a laser speckle pattern is projected on the thickness side of the sample between two notches. The sample is strained by $2 \%, 4 \%, 8 \%, 12 \%$ at constant nominal contact pressures of 15,30 , and $45 \mathrm{MPa}$. The sample is strained at a rate of $2 \mathrm{~mm} / \mathrm{min}$. A new sample is used for each combination of strain and nominal pressure.

\subsubsection{Measuring the real area of contact}

After unloading the samples, the real area of contact of the deformed sample is determined using the surface height distribution function $[6,11]$. The height distribution function is derived from the measured height data. Furthermore, it is important to use a representative area of the sheet surface. Shisode et al. [11] analyzed measurement areas of different sizes to determine the height distribution functions and concluded that the measurement area of $2 \mathrm{~mm} \times$ $2 \mathrm{~mm}$ is sufficient to represent the statistics of the surface topography. Therefore, the measurement area of $2 \mathrm{~mm} \times 2 \mathrm{~mm}$ is used to determine the height distribution function. Figure 3 shows an example of the derived height distribution function of deformed and undeformed sample. In the deformed sample, the taller asperities deform resulting in local peak ( $h_{\mathrm{pk}}$ in Fig. 3).

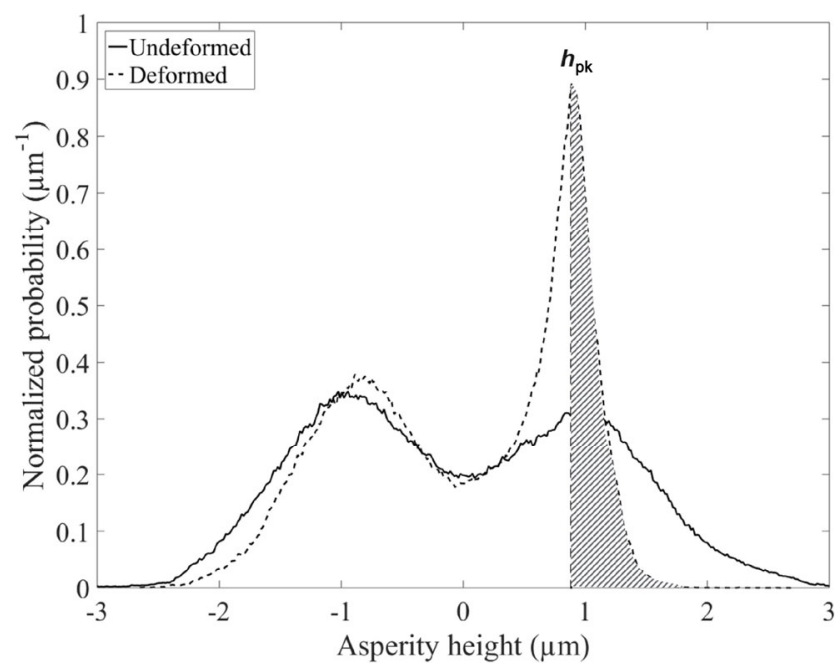

Fig. 3 Surface height distribution function of deformed and undeformed sample.
The real area of contact $\alpha$ is estimated using the local peak height $\left(h_{\mathrm{pk}}\right)$ and height distributionn function as follows [6, 11],

$$
\alpha=\int_{h_{\mathrm{pk}}}^{\infty} \phi_{\mathrm{def}}(z) \mathrm{d} z
$$

where $\phi_{\text {def }}(z)$ is the height distribution function of the deformed surface.

\subsection{Results}

A separate sample is used for each combination of nominal pressure and strain. However, to visualize the progress of asperity deformation, additional experiments are performed on samples 2 and 3 using the same sample at constant nominal pressure of $15 \mathrm{MPa}$ and uniaxial tensile strains of $2 \%, 4 \%, 8 \%$, and $12 \%$. Small parts of the measured height data are shown in Figs. 4 and 5 for samples 2 and 3 respectively. A decrease in asperity height due to flattening can be seen as the strain increases at constant nominal pressure. Height distribution functions derived from the measured height data of the undeformed and deformed surfaces are shown in Fig. 6. Height distribution functions at nominal pressure of $30 \mathrm{MPa}$ and longitudinal strains up to $12 \%$ are plotted. Comparison of the undeformed and deformed distribution functions clearly shows the surface deformation. The real area of contact is determined as per Eq. (1) using the local peak height $h_{\mathrm{pk}}$ and height distribution function of the deformed surface.

The fractional real area of contact as a function of longitudinal strain at a constant nominal pressure for all the samples are shown in Fig. 7. The results show that the real area of contact increases monotonically with increase in longitudinal strain at a constant pressure. The real area of contact shows a higher increase at the smaller strains. By increasing the strain, the skewness in height distribution of the samples increases rapidly, and the texture on the surface vanishes. Fading of the texture on the sheet metal can influence the frictional behavior of the sheet metal. It can also affect the paint appearance of the sheet metal specifically for the areas which undergo large strains. The results show that the texture (roughness) of sample 3 is almost lost following $8 \%$ of strain at $30 \mathrm{MPa}$ (Fig. 6). 

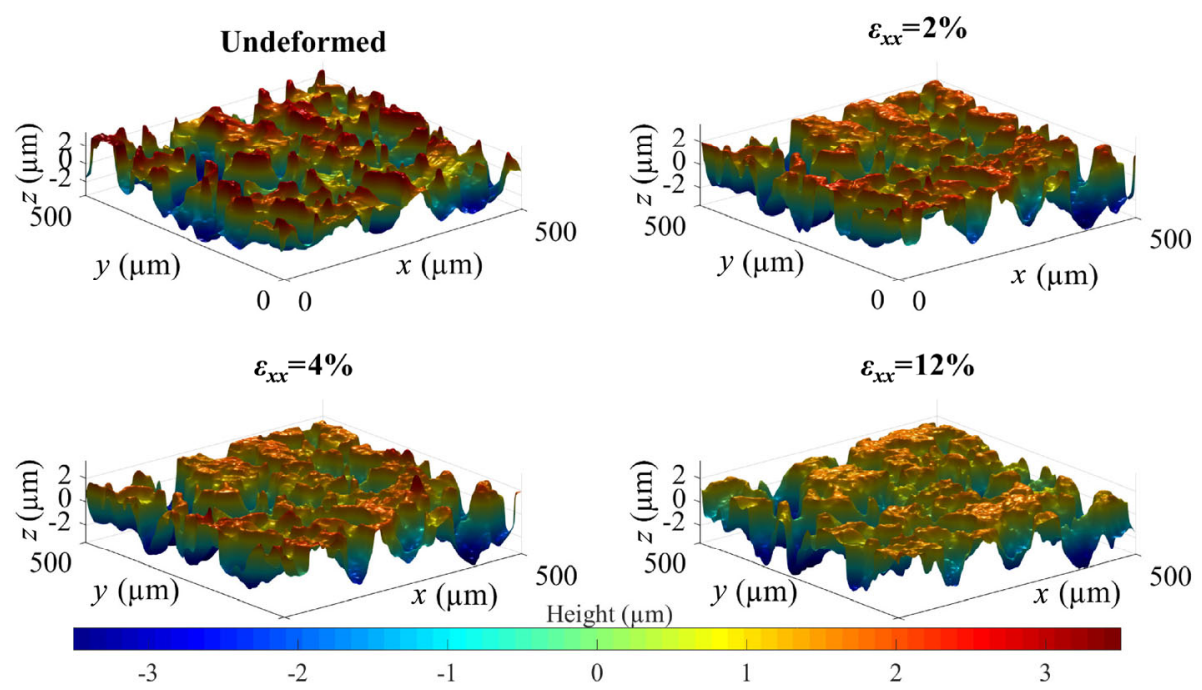

Fig. 4 Evolution of surface topography due to combined normal load (15 MPa) and longitudinal strain for sample 2 (the same sample is used for all experiments).
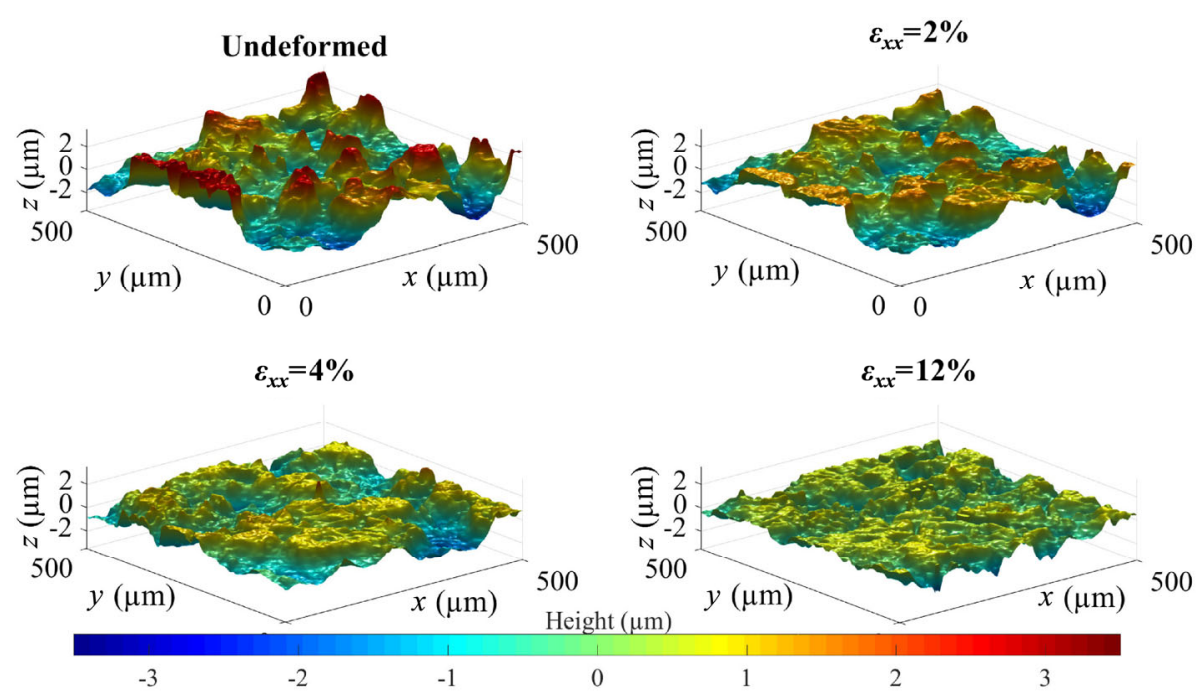

Fig. 5 Evolution of surface topography due to combined normal load (15 MPa) and longitudinal strain for sample 3 (the same sample is used for all experiments).

It is noticeable that the real area of contact for GI samples is higher than uncoated DC04 sample. This is because the hardness of the GI sheet is lower than the uncoated sheet due to the softer zinc coating. Furthermore, the real area of contact is highest for sample 3 (coating thickness $=23 \mu \mathrm{m}$ ) which demonstrates the influence of coating thickness. Also, the surface texture of sample 3 is much different (with higher $R_{\mathrm{sm}}$ value) compared to samples 1 and 2 (Fig. 2). Moreover, the substrate in sample 3 is the strongest among all samples. This demonstrates the major influence of coating thickness in asperity deformation while the influence of substrate diminishes with increase in coating thickness as concluded by Halling and Arnell [19]. The real contact areas of samples 1 and 2 are similar although sample 2 has a coating thickness twice the sample 1 . However, sample 2 has a higher roughness compared to sample 1 which indicates that the surface roughness plays a significant role in asperity deformation as well. It should be noted that despite a similar real area of contact, the resultant height distributions of the samples 1 and 2 after deformation are different (Fig. 6). The results show that as the skewness of height distribution increases due to 

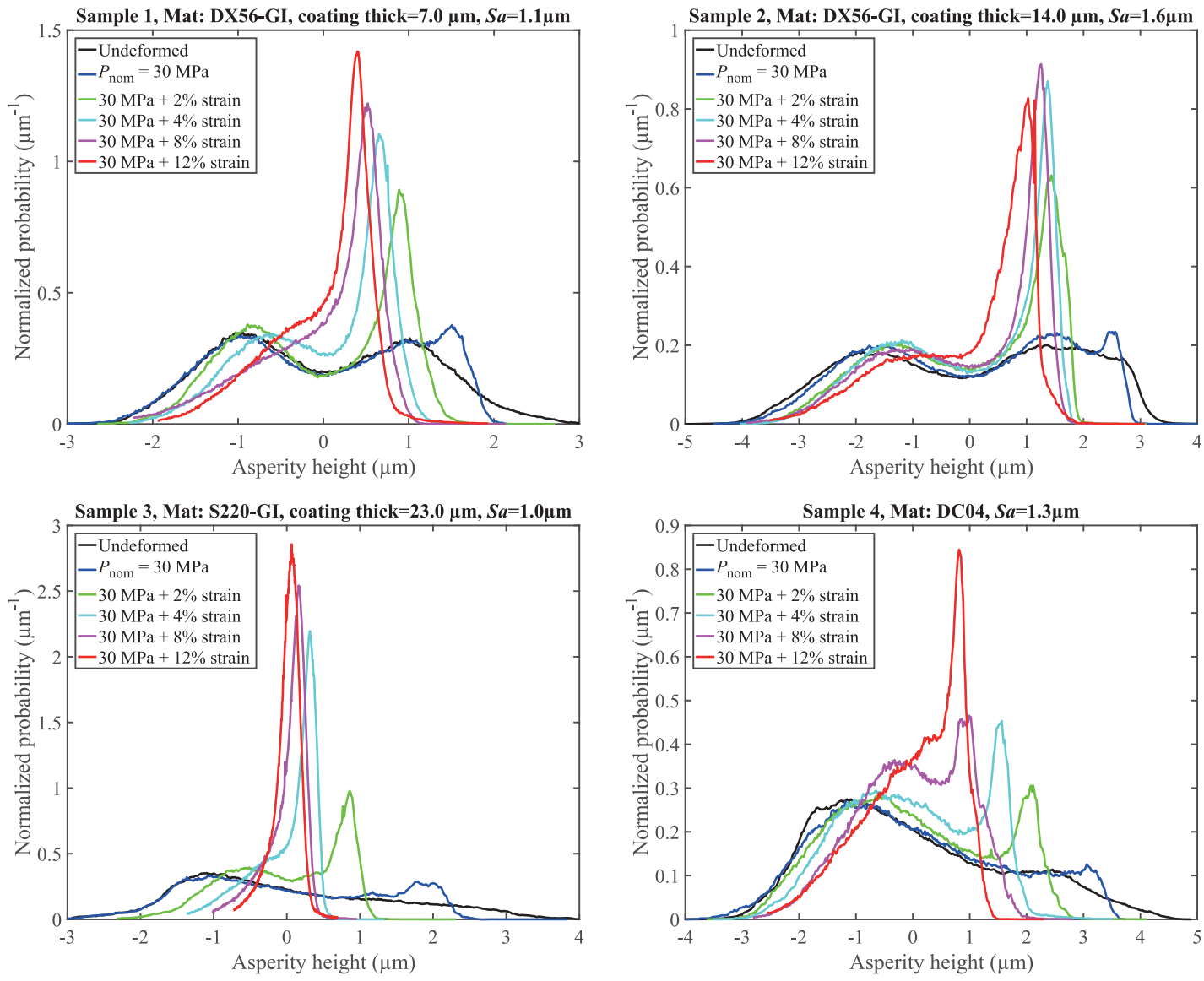

Fig. 6 Surface height distribution functions of undeformed and deformed samples.
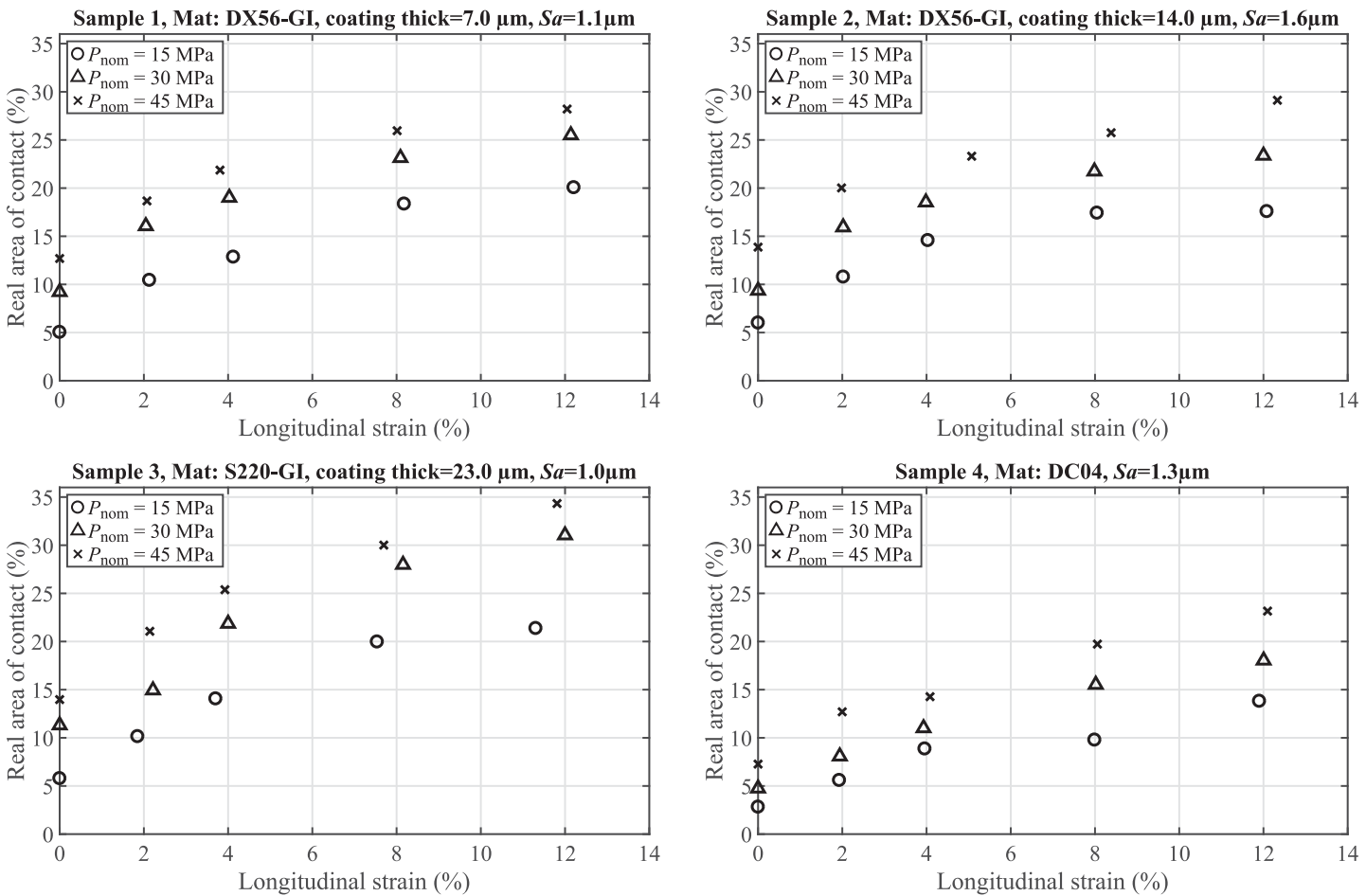

Fig. 7 Experiments: real area of contact vs. uniaxial tensile strain at 3 different nominal pressures. 
asperity deformation, the bimodal distribution reduces to almost a single peak in the case of sample 1 at high strains while it remains for sample 2. On the contrary, the bimodal distribution in sample 4 becomes more pronounced with increase in strain.

For the samples investigated in this study, coating thickness plays a significant role in asperity deformation while the effect of substrate is minor. In general, by increasing the surface (asperities) deformation, the shape of the height distribution profile changes and becomes more skewed. The results also suggest the influence of surface roughness and surface texture on asperity deformation but it is difficult to draw any conclusion using the available experimental data. Hence, 2D plane strain FE analyses are performed to understand the effect of each parameter on the real area of contact.

\section{Effect of different parameters on real area of contact}

Using FE simulations, it is possible to determine the influence of each individual parameter on the real area of contact under combined normal load and subsurface strain. 3D FE simulations can be done for more accurate predictions but modeling a 3D surface at the asperity level is complicated and computationally expensive. Hence, 2D plane strain FE simulations are chosen for sensitivity analysis of different parameters on the real area of contact. The parameters that are varied in this study are coating thickness, surface roughness, and surface texture. The $2 \mathrm{D}$ profiles derived from GI samples (see Table 1 for specifications) are used. Figure 8 shows the 2D profiles of the undeformed samples 1, 2 and 3. Samples 1 and 2 have a similar surface texture, and height distribution function which are different from sample 3. Hence, profiles of samples 1 (profile 1) and 3 (profile 3 ) are used for the numerical study by varying different parameters. To understand the influence of coating thickness, profile 1 with coating thickness of 7 and $14 \mu \mathrm{m}$ are modeled. Furthermore, to investigate the influence of surface roughness, profile 1 with surface roughness of $1.1 \mu \mathrm{m}$ and profile 1 with a scaled roughness of $1.6 \mu \mathrm{m}$ are modeled while maintaining the same coating thickness. Also, the results from profile 1 and 3 which have a similar surface roughness are compared to understand the effect of surface texture while maintaining the same coating thickness.

\subsection{FE modeling}

Figure 9 shows the details of a 2D plane strain model. The total profile length of $3 \mathrm{~mm}$ is modeled to include enough asperities to have a representative model. The substrate thickness is equal to $0.7 \mathrm{~mm}$. In the FE model, finer mesh density is used in the coating with element

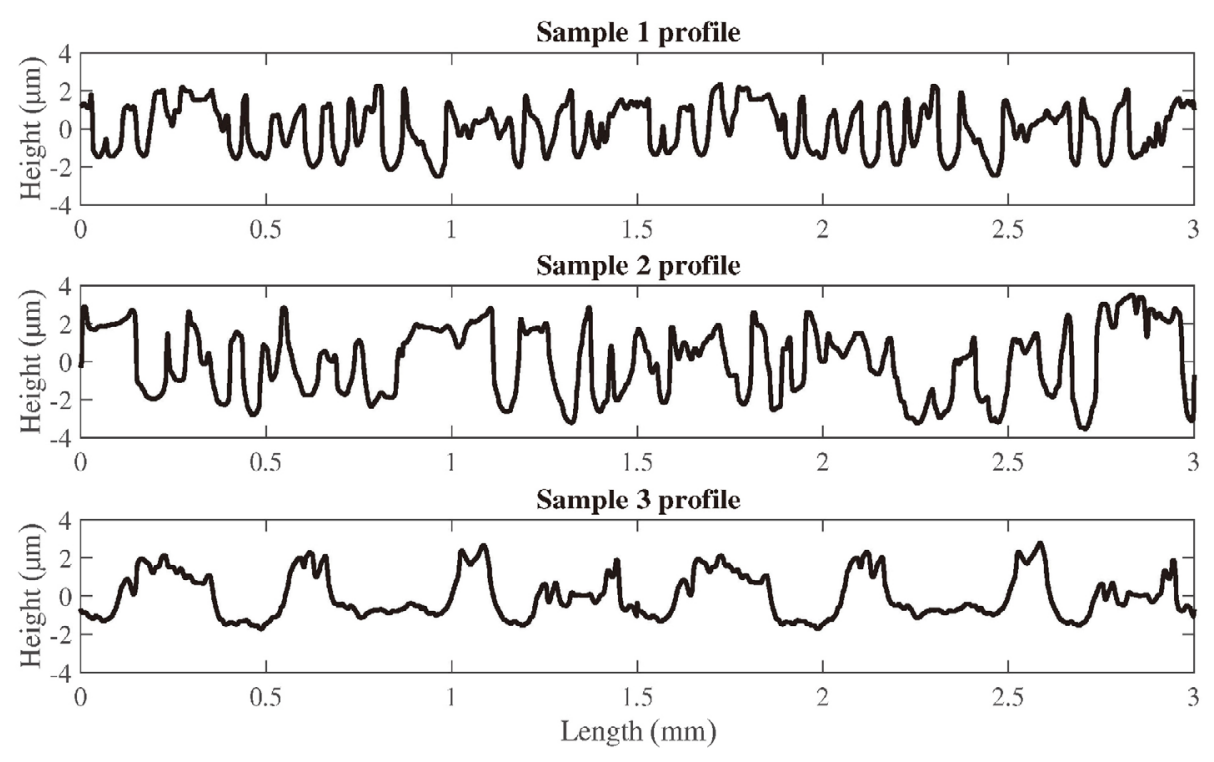

Fig. 82 profile of samples $1\left(R_{\mathrm{a}}=1.1 \mu \mathrm{m}\right), 2\left(R_{\mathrm{a}}=1.6 \mu \mathrm{m}\right)$, and $3\left(R_{\mathrm{a}}=1.0 \mu \mathrm{m}\right)$. 


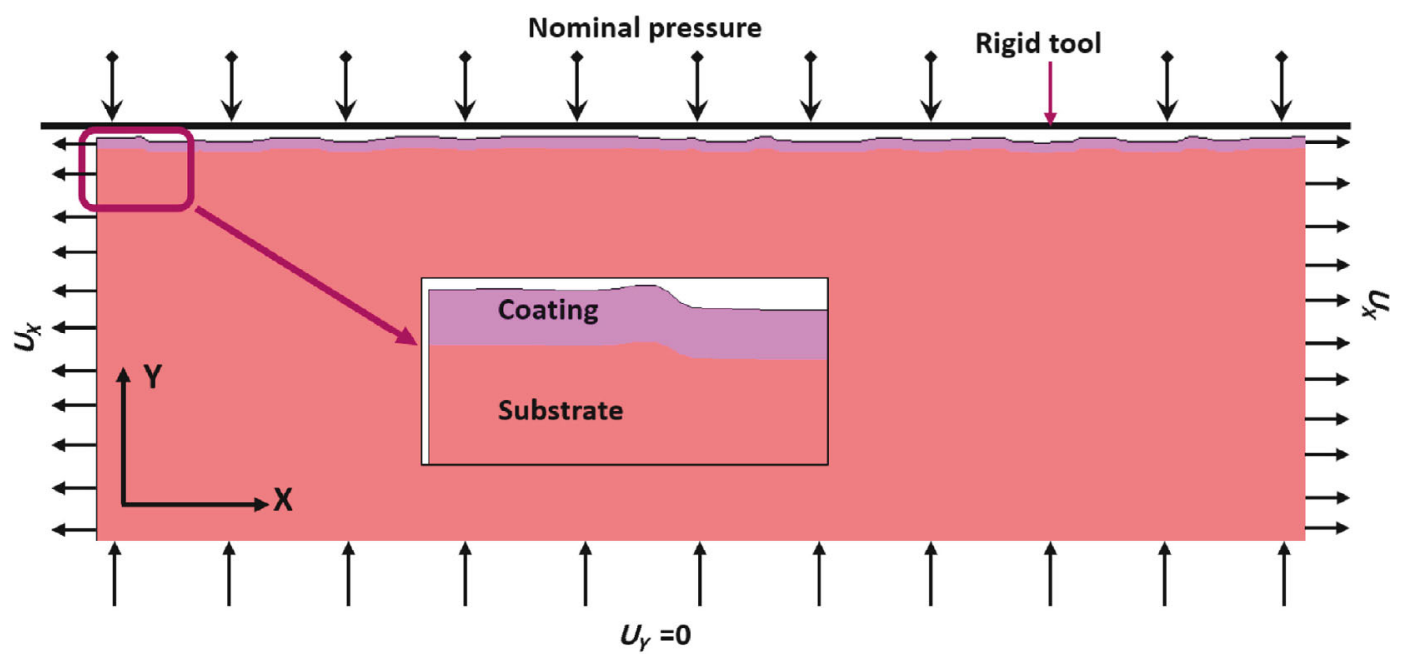

Fig. 9 FE model details (profile 1).

edge length less than the surface height measurement resolution $(1.3 \mu \mathrm{m})$. Plane strain quadrilateral elements (4 node, full integration) are used. The mesh is gradually coarsened in the substrate.

\subsection{Material properties}

The stress-strain curves of zinc coating [20] and steel substrates [11] are shown in Fig. 10. For steel substrates, the Young's modulus $=210 \mathrm{GPa}$ and Poisson's ratio $=$ 0.3 . For zinc coating, the Young's modulus $=70 \mathrm{GPa}[20]$ and Poisson's ratio $=0.3$ [21].

\section{Assumptions:}

1) The tool is flat and rigid as the hardness of sapphire is much higher than the sample materials;

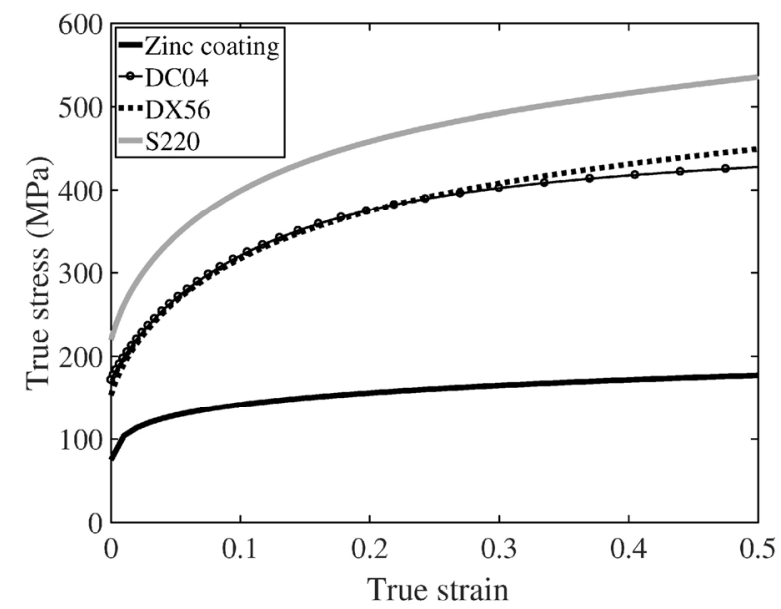

Fig. 10 Material flow curves. Reproduced with permission from Ref. [11], C) Elsevier, 2020.
2) the coefficient of friction of 0.08 is used between the rough surface and the tool. The coefficient of friction between a mirror finished sapphire surface and GI sample is determined by a linear friction tester [22];

3) the coating thickness is uniform and bonded perfectly to the substrate;

4) elastic-plastic material response of coating and substrate is modeled by von Mises yield criterion.

For simplicity, a constant substrate DX56 with zinc coating is used in the FE analyses. Which means that the sensitivity of the substrate material is not studied because the soft coating dominates the asperity flattening [19]. The material properties for other substrates are still required in the analytical model presented in Section 4. In the FE analysis, the tool is moved downward to apply a normal load corresponding to a nominal pressure of $15 \mathrm{MPa}$. Afterwards, a longitudinal strain is gradually applied by specifying lateral displacements on each side. As the material is strained, its nominal contact area with the tool increases which reduces the nominal pressure at constant normal load. Hence the normal force is increased in the same proportion with nominal contact area to keep the nominal pressure constant. Results are post processed to determine the real area of contact at a nominal pressure of $15 \mathrm{MPa}$ and a longitudinal strain up to $10 \%$. The real area of contact is determined by identifying the nodes in contact with the tool from which the total contact length and the contact area are determined. 


\subsection{Discussion}

The calculated fractional real area of contact for all profiles based on FE simulations are shown in Fig. 11. The evolution of real area of contact from plane strain FE simulations shows the same trend as in the experiments. The real area of contact for the profile with $14 \mu \mathrm{m}$ coating thickness is higher compared to the profile with $7 \mu \mathrm{m}$ coating thickness which confirms the effect of coating thickness on the real area of contact. This is because of the decrease in normal stiffness at a higher coating thickness. Therefore, the higher coating thickness allows better redistribution of the applied load. On the other hand, a profile of higher roughness has a lower real area for the same coating thickness and loading conditions. At constant normal load, the strain hardening is higher in the surface with higher roughness due to the taller asperities as compared to the smooth surface. The effect of coating thickness and surface roughness have opposite effects which explains the similarity of the experimental results of samples 1 and 2. The surface texture or the profile shape also influences the asperity deformation. For example, profiles 1 $\left(R_{\mathrm{sm}}=66 \mu \mathrm{m}\right)$ and $3\left(R_{\mathrm{sm}}=153 \mu \mathrm{m}\right)$ have the same coating thickness and similar roughness but the real area of contact for profile 3 increases more rapidly after a certain strain $(>5 \%)$ which can be attributed to the profile shape or the surface texture. In the case of profile 3 , the asperities deform gradually up

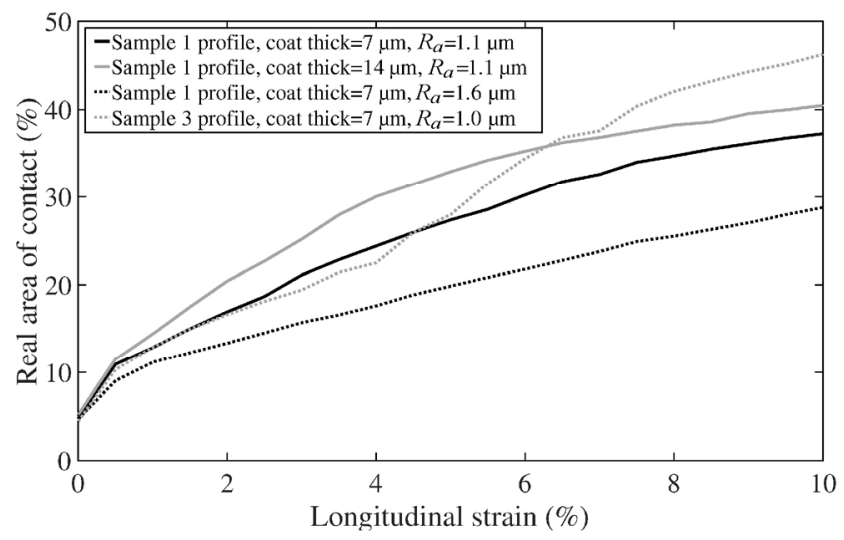

Fig. 11 Effect of coating thickness, roughness and height distribution on real area of contact at nominal pressure of $30 \mathrm{MPa}$ obtained from FE results.

to a strain of $5 \%$ but at higher strains, the asperities join together and the flat islands suddenly come into contact with the tool. This results in a better redistribution of the applied load and rise in real area of contact.

To check the hypothesis of increase in real area of contact due to more uniform distribution of the applied load, the strain energy density distribution in the coating layer is plotted. The strain energy density is chosen because it is highly related to material hardening and combines the effects of stresses and strains. The total elemental strain energy density distribution is plotted for each profile as shown in Figs. 12 and 13. The difference in the distributions is clearly visible. Figure 12(a) shows that with increase

\section{(a) $\varepsilon_{x x}=10 \%$}

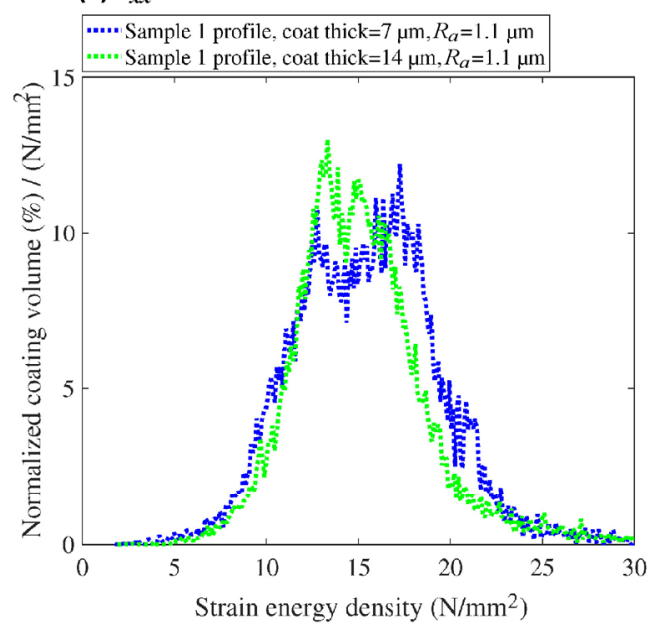

\section{(b) $\varepsilon_{x x}=10 \%$}

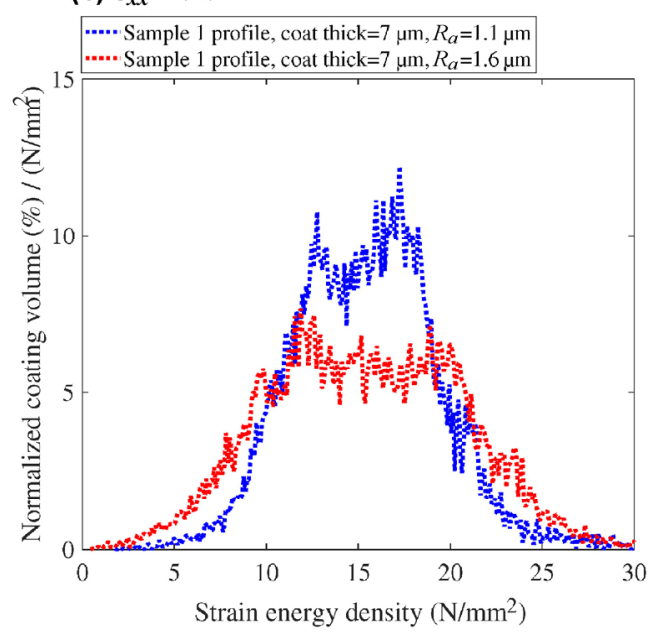

Fig. 12 FE analysis results-total strain energy distribution in coating at $P_{\text {nom }}$ of $15 \mathrm{MPa}$ and $\varepsilon_{x x}$ of $10 \%$. (a) Influence of coating thickness and (b) influence of profile roughness. 

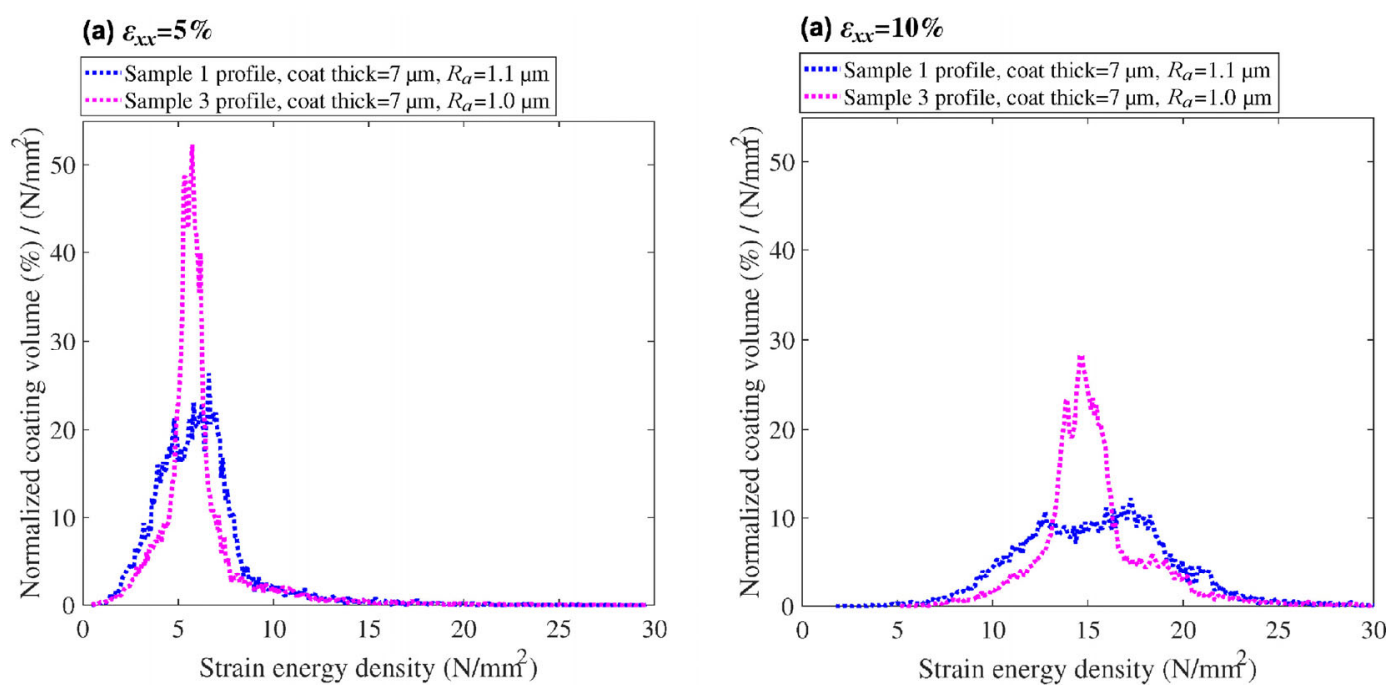

Fig. 13 FE analysis results-total strain energy distribution in coating at $P_{\text {nom }}$ of $15 \mathrm{MPa}$ and $\varepsilon_{x x}$ of $5 \%$ and $10 \%$ showing influence of profile shape.

in zinc coating thickness (at constant roughness), the peak of the distribution becomes narrow which represents a more uniform distribution of the applied load, therefore higher real area of contact. Furthermore, a profile of low roughness (at constant coating thickness), has a narrower peak (see Fig. 12(b)) compared to high roughness profile. Figure 13 shows the effect of surface texture (profile shape) at 5\% and 10\% longitudinal strains. A narrower peak can be seen in profile 3 compared to profile 1 especially at higher strains (> 5\%). Due to this, the real area of contact in profile 3 is much higher at higher strains $(>5 \%)$. This is also observed in the experimental results in which the real areas of contact for samples 1 and 3 are similar at lower strains but the difference increases at higher strains (see experimental results of samples 1 and 3 in Fig. 7).

\section{An analytical model to estimate real area of contact for combined normal load and sub-surface strain}

2D models [16, 17] were proposed in the past for combined effect of normal load and bulk strain. But these models are not suitable for randomly distributed and arbitrary shaped asperities. Westeneng [6] adopted the 2D models to include the effect of arbitrary shaped asperities and distribution by introducing a surface topography parameter called asperity density $\left(\rho_{\mathrm{a}}\right)$. In this study, Westeneng model [6] is used to estimate the real area of contact for GI and uncoated steel sheets. The required asperity density parameter for each sample is determined using the experimental results.

\subsection{Description of rough surface}

The measured height data of the rough surface is modeled by bars $[6,11]$ as shown in in Fig. 14(a). Each bar has a width equal to the measurement resolution $(1.3 \mu \mathrm{m})$ and height equal to the height of the measured surface point. The tool displacement due to crushing of bars is represented by tool position $d$ from the mean plane and the rise of non-contacting asperities is described by the uniform rise $U[6,11]$. The height data of the measured surface is fitted by the height distribution function $\phi(z)$. The height distribution function is used in the analytical model to describe the rough surface. In the current model, B-spline function [23] using 10 cubic splines is fitted as shown in Fig. 14(b).

\subsection{Model description}

Westeneng [6] derived the following analytical relation to determine the fractional real area of contact $\alpha_{\varepsilon}$ as a function of uniaxial strain $\varepsilon$ in the sheet. The model assumes a smooth and rigid tool plastically deforming soft asperities modeled as an ideal plastic material. 

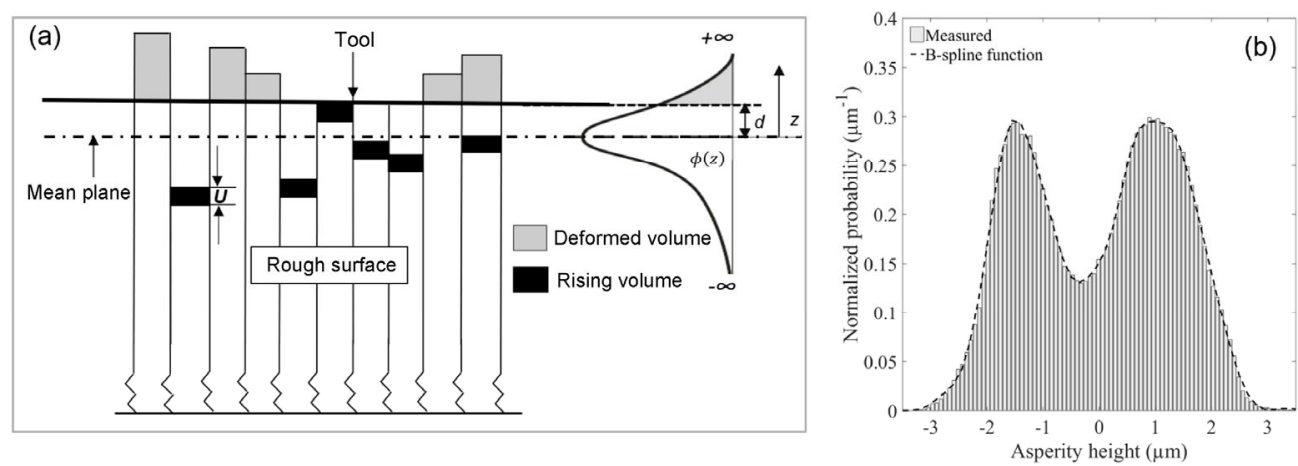

Fig. 14 (a) Deformation and rise of asperities. Reproduced with permission from Ref. [11], (C) Elsevier, 2020. (b) Fitting of height distribution data by B-spline function (sample 1).

$$
\frac{\mathrm{d} \alpha_{\varepsilon}}{\mathrm{d} \varepsilon}=l V \frac{\mathrm{d} \alpha_{\varepsilon}}{\mathrm{d}\left(U_{\varepsilon}-d_{\varepsilon}\right)}
$$

where $l$ is the mean half asperity spacing and $V$ is the velocity parameter defined as,

$$
V=\frac{v_{\mathrm{d}}+v_{\mathrm{u}}}{\dot{\varepsilon} l}
$$

$v_{\mathrm{d}}$ is downward velocity of the deforming asperities and $v_{\mathrm{u}}$ is upward velocity of the non-contacting surface. Westeneng [6] approximated the velocity parameter using a relation proposed by Sutcliffe [16] for wedge shaped asperities deforming under combined normal load and sub-surface strain. Sutcliffe [16] performed a slip-line analysis under combined normal load and sub-surface strain assuming an ideal plastic material behavior. Using the slip-line analysis, a relation between the slip angle called $\Phi$ and the velocity parameter is derived as follows,

$$
V=-0.184+1.21 \exp (1.47 \Phi)
$$

$\Phi[16]$ is defined as,

$$
\Phi=\frac{H_{\text {eff }}}{4 k}\left(1-\alpha_{\varepsilon}\right)
$$

where $H_{\text {eff }}=\frac{P_{\text {nom }}}{\alpha_{\varepsilon}}$ is the effective hardness and $k$ is the shear strength of the workpiece material. $k=\frac{H}{B \sqrt{3}}$ following a von Mises criterion under pure shear. $H$ is the initial hardness of the workpiece material and $B$ is the hardness factor and is equal to 2.8 for metals as determined by Tabor [24].

$l$ in Eq. (2) is the mean half asperity spacing which is determined as [6],

$$
\begin{aligned}
& l=\frac{\sqrt{\bar{\alpha}}}{2} \\
& \bar{\alpha}=\frac{1}{\rho_{\mathrm{a}}}
\end{aligned}
$$

where $\bar{\alpha}$ is the mean apparent contact area of single asperity, $\rho_{\mathrm{a}}$ is the number of asperities in contact with tool per unit area. Definitions of $l$ and $\bar{\alpha}$ are true for uniformly distributed asperities of the same geometryas assumed by Sutcliffe [16]. Furthermore, $l$ changes during straining. This is because as the surface deforms, the asperities in contact with the tool increase which increases the asperity density $\rho_{\mathrm{a}}$ and reduces the mean half asperity spacing $l$. Hence, $l$ is a function of asperity density and $\alpha_{\varepsilon}$, where, $\alpha_{\varepsilon}$ is introduced to account for the decrease in $l$ with increase in real area of contact as follows,

$$
l=\frac{1}{2 \sqrt{\rho_{\alpha} \alpha_{\varepsilon}}}
$$

The asperity density $\rho_{\mathrm{a}}$ for any random surface is approximated by a fitting parameter. A relation to determine the asperity density $\rho_{\mathrm{a}}$ and its parameters is described in Section 4.3. Equation (9) is used to determine the fractional real area of contact $\alpha_{\varepsilon}$.

$$
\alpha_{\varepsilon}=\int_{d_{\varepsilon}-U_{\varepsilon}}^{\infty} \phi(z) \mathrm{d} z
$$

where $\phi(z)$ is the height distribution function of undeformed surface. Substituting Eqs. (9) into (2) yields,

$$
\frac{\mathrm{d} \alpha_{\varepsilon}}{\mathrm{d} \varepsilon_{\text {total }}}=l V \phi\left(d_{\varepsilon}-U_{\varepsilon}\right)
$$


To determine $\alpha_{\varepsilon}$ at strain $\varepsilon_{\text {total }}$, an incremental solution scheme is used as presented in Fig. 15. $\alpha_{\mathrm{p}}$ is the real area of contact at nominal pressure $P_{\text {nom }}$ in the absence of strain $\left(\varepsilon_{\text {total }}=0\right)$, and $d_{\mathrm{p}^{\prime}} U_{\mathrm{p}}$ are the corresponding tool position and uniform rise of asperity respectively. $\alpha_{\mathrm{p}^{\prime}} d_{\mathrm{p}^{\prime}}$ and $U_{\mathrm{p}}$ are determined using the normal load flattening model.

In the literature, analytical models [7-11] are proposed to determine the real area of contact for coated sheet under a normal load. Recently, a semi-analytical normal load contact model is proposed by Shisode et al. [11]. The model considers the material behavior of coating and substrate, measured surface topography, and coating thickness. More importantly, the model also accounts for the material hardening. The mechanical behavior of ellipsoidal asperties of different sizes is described by contact pressure at different levels of asperity flattening. For this purpose, FE analyses are performed on asperities with range of geometrical parameters to determine the contact pressure at different flattening levels. The database of contact pressure is developed for a given combination of coating thickness and coating-substrate materials. The developed database of contact pressure is used to determine the contact force on each asperity of the measured rough surface at a given tool position based on the asperity shape and the flattened volume. The equilibrium position of the tool is determined by solving the force balance and volume conservation equations from which the asperity deformation, uniform rise of non-contacting asperities, and real area of contact $\alpha_{\mathrm{p}}$ at applied nominal pressure is determined. Refer [11] for more details on the methodology and solution scheme.

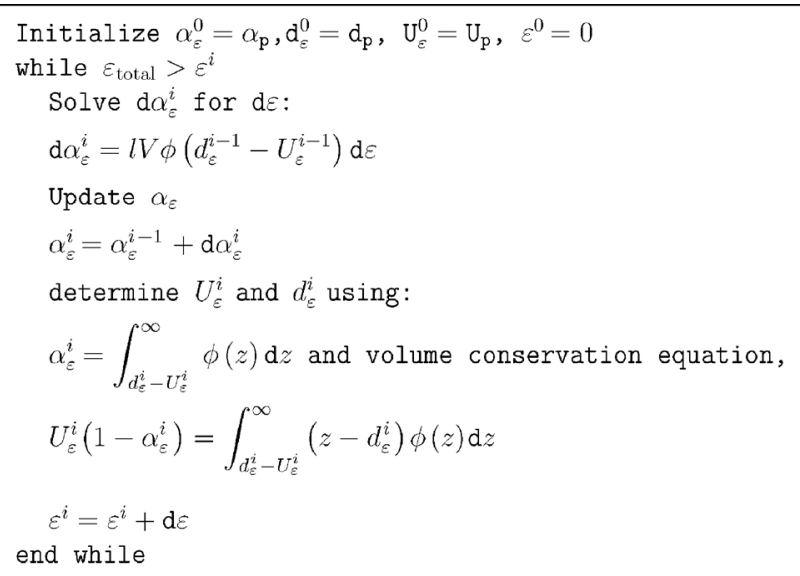

Fig. 15 Solution scheme to determine $\alpha_{\varepsilon}$.
This model is used in this study to determine the initial values $\alpha_{\mathrm{p}^{\prime}} d_{\mathrm{p}^{\prime}}$ and $U_{\mathrm{p}}$ at nominal pressure $P_{\text {nom }}$ required as the input in Westeneg's model.

\subsection{Model results and discussion}

The model to determine the real area of contact under combined normal load and sub-surface strain is implemented in MATLAB. Asperity density $\rho_{\mathrm{a}}$ which is necessary to determine the mean half asperity spacing $l$ in Eq. (10) is unknown. $\rho_{\mathrm{a}}$ can be determined using the 9-point summit rule [25] on measured surface height data. A summit is defined as the surface point with height more than its surrounding points. However, the result is highly dependent on the resolution of surface measurement. Furthermore, $\rho_{\mathrm{a}}$ increases with the real area of contact because the number of asperities in contact with the tool increases. Owing to the limitations and complexities, an asperity density is often calibrated for each specific surface. In this case, experimental results are used to calibrate asperity density. The asperity density is modeled by a power law function of the nominal pressure, $\rho_{\mathrm{a}}=c P_{\text {nom }}^{\mathrm{n}}$ [26]. Constants $c$ and $n$ are determined so as to reduce the difference between the model results and the experiments. For this purpose, a MATLAB optimization algorithm fmincon is used to minimize the cumulative root mean square (RMS) error in real area of contact between the model results and the experiments at all experimental data points. Constants $c$ and $n$ are optimized which results in an RMS error $<2 \%$ in the prediction of real area of contact. For samples 1 and 2: $c=5 \times 10^{4}, n=0.4$, for sample 3: $c=3.5 \times 10^{4}, n=0.23$, and for sample 4: $c=$ $5.7 \times 10^{4}, n=0.47$. The model results using the adopted asperity density and experimental results are shown in Fig. 16. The asperity density for samples 1 and 2 is the same which might be due to having similar (bimodal) height distributions.

\section{Conclusions}

A new experimental setup is developed to measure the real area of contact under combined normal load and sub-surface strain. GI samples of different surface topographies and zinc coating thicknesses are used for the experimental investigation. The real area of 

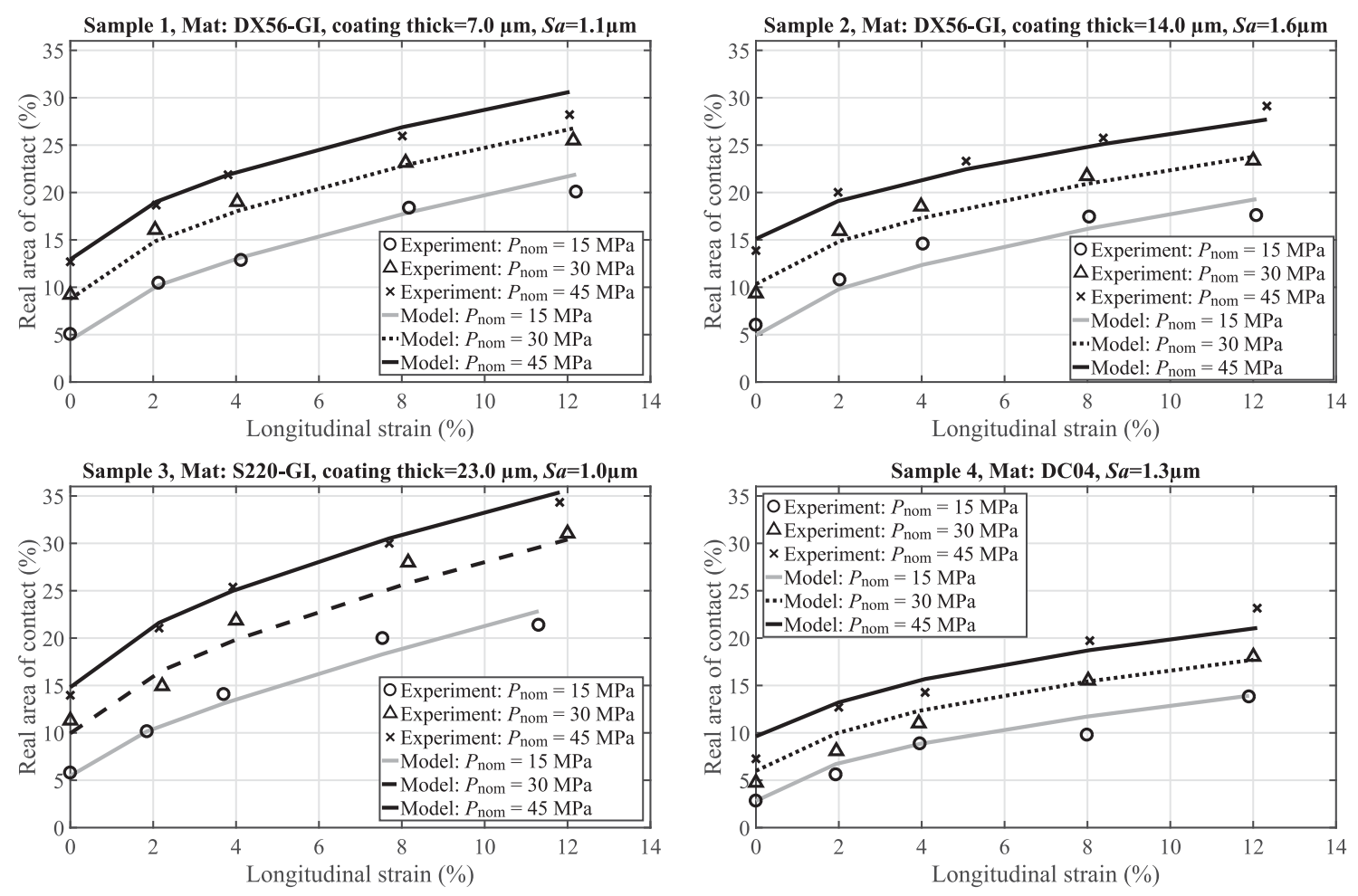

Fig. 16 Real area of contact: experiments vs. model.

contact increases monotonically with strain for all the samples at constant nominal pressure with higher rate at lower strains compared to higher strains. The plane strain FE simulations are performed to understand the trend observed in the experiments and the effect of different parameters. The real areas of contact determined using the FE simulations show the same trend as experiments. Influence of coating thickness, surface roughness, and surface texture on real area of contact under combined normal load and sub-surface strain is determined using FE simulations. From the experiments and FE simulations, it can be concluded that, the real area of contact under combined normal load and sub-surface strain increases with coating thickness (soft coating on hard substrate) and decreases with surface roughness. The surface texture also has significant influence on asperity deformation. For instance, the real area of contact is higher for surfaces with higher mean peak spacing $\left(R_{\mathrm{sm}}\right)$ while having the same surface roughness and coating thickness. The Westeneng model originally developed for uncoated sheets to determine the real area of contact under combined normal load and sub-surface strain is adopted for the coated sheets. The model is calibrated using the available experimental results. The calibrated model can be used for accurate modeling of friction and wear in sheet metal forming processes.

\section{Acknowledgements}

This research was carried out under project number S22.1.14520b in the framework of the Partnership Program of the Materials Innovation Institute M2i (www.m2i.nl) and the Technology Foundation TTW (www.stw.nl), which is part of the Netherlands Organization for Scientific Research (www.nwo.nl). The authors would like to greatly acknowledge Dr.ir. Jeroen van Beeck, Dr.ir. Carel ten Horn, Dr.ir. Matthijs Toose, and Marco Appelman from Tata Steel Europe for technical guidance and assistance during the experiments.

Open Access This article is licensed under a Creative Commons Attribution 4.0 International License, which permits use, sharing, adaptation, distribution and reproduction in any medium or format, as long as you give appropriate credit to the original author(s) and the source, provide a link to the Creative Commons licence, and indicate if changes were made. 
The images or other third party material in this article are included in the article's Creative Commons licence, unless indicated otherwise in a credit line to the material. If material is not included in the article's Creative Commons licence and your intended use is not permitted by statutory regulation or exceeds the permitted use, you will need to obtain permission directly from the copyright holder.

To view a copy of this licence, visit http://creativecommons.org/licenses/by/4.0/.

\section{References}

[1] Bay N, Wanheim T. Real area of contact and friction stress at high pressure sliding contact. Wear 38(2): 201-209 (1976)

[2] Bay N. Friction stress and normal stress in bulk metalforming processes. Journal of Mechanical Working Technology 14(2): 203-223 (1987)

[3] Wanheim T, Bay N, Petersen A. A theoretically determined model for friction in metal working processes. Wear 28(2): 251-258 (1974)

[4] Chang W R, Etsion I, Bogy D. B. An elastic-plastic model for the contact of rough surfaces. Journal of Tribology 109(2): 257-263 (1987)

[5] Zhao Y, Maietta D M, Chang L. An asperity microcontact model incorporating the transition from elastic deformation to fully plastic flow. Journal of Tribology 122(1): 86-93 (2000)

[6] Westeneng J D. Modelling of contact and friction in deep drawing processes. Ph.D Thesis. Netherlands (Twente): University of Twente, 2001.

[7] Chen Z, Goltsberg R, Etsion I. A universal model for a frictionless elastic-plastic coated spherical normal contact with moderate to large coating thicknesses. Tribology International 114: 485-493 (2017)

[8] Chang W R. An elastic-plastic contact model for a rough surface with an ion-plated soft metallic coating. Wear 212(2): 229-237 (1997)

[9] Mulki H, Mizuno T. Contact mechanics of zinc-coated steel sheets. Wear 199(2): 260-267 (1996)

[10] Shisode M, Hazrati J, Mishra T, de Rooij M, van den Boogaard T. Multi-scale contact modeling of coated steels for sheet metal forming applications. Key Engineering Materials 767: 223-231 (2018)

[11] Shisode M, Hazrati J, Mishra T, de Rooij M, van den Boogaard A. Semi-analytical contact model to determine the attening behavior of coated sheets under normal load. Tribology International 106182 (2020).
[12] Wichern C, De Cooman B, and Van Tyne C. Surface roughness of a hot-dipped galvanized sheet steel as a function of deformation mode. Journal of Materials Processing Technology 160(3): 278-288 (2005)

[13] Wichern C, De Cooman B, Van Tyne C. Surface roughness changes on a hot-dipped galvanized sheet steel during deformation at low strain levels. Acta Materialia 52(5): 1211-1222 (2004)

[14] Wang Z, Yoshikawa Y, Suzuki T, Osakada K. Determination of friction law in dry metal forming with dlc coated tool. CIRP Annals 63(1): 277-280 (2014)

[15] Nielsen C V, Martins P A, Bay N. Modelling of real area of contact between tool and workpiece in metal forming processes including the Influence of subsurface deformation. CIRP Annals 65(1): 261-264 (2016)

[16] Sutcliffe M. Surface asperity deformation in metal forming processes. International Journal of Mechanical Sciences 30(11): 847-868 (1988)

[17] Wilson W, Sheu S. Real area of contact and boundary friction in metal forming. International Journal of Mechanical Sciences 30(7): 475-489 (1988)

[18] Ike H, Makinouchi A. Effect of lateral tension and compression on plane strain flattening processes of surface asperities lying over a plastically deformable bulk. Wear, 140(1): 17-38 (1990)

[19] Halling J, Arnell R. Ceramic coatings in the war on wear. Wear 100(1-3): 367-380 (1984)

[20] Song G, Sloof W, Pei Y, De Hosson J T M. Interface fracture behavior of zinc coatings on steel: Experiments and finite element calculations. Surface and Coatings Technology 201(7): 4311-4316 (2006)

[21] Pei Y T, Song G, Sloof W G, De Hosson J T M. A methodology to determine anisotropy effects in non-cubic coatings. Surface and Coatings Technology 201(16-17): 6911-6916 (2007)

[22] Mishra T, de Rooij M, Shisode M, Hazrati J, Schipper D J. Characterization of interfacial shear strength and its effect on ploughing behaviour in single-asperity sliding. Wear 436: 203042 (2019)

[23] Hol J. Multi-scale friction modeling for sheet metal forming. Ph.D Thesis. Netherlands (Twente): University of Twente, 2013.

[24] Tabor D. The hardness of solids. Review of Physics in Technology 1(3): 145 (1970)

[25] de Rooij M. Tribological aspects of unlubricated deep drawing processes. Ph.D Thesis. Netherlands (Twente): University of Twente, 1998.

[26] Hol J, Meinders V T, de Rooij M B, van den Boogaard A H. Multi-scale friction modeling for sheet metal forming: The boundary lubrication regime. Tribology International 81: $112-128(2015)$ 


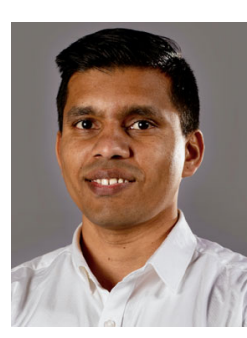

Meghshyam SHISODE. He received his bachelor degree in mechanical engineering from Savitribai Phule Pune University, India (formerly known as University of Pune) and master degree in mechanical engineering from Indian Institute of
Science, Bangalore, India. Then he worked in General Electric (aviation) as a design engineer. Later, he earned his Ph.D. in 2020 from nonlinear solid mechanics research group at University of Twente, The Netherlands. His research interests include tribology, multi-scale friction modeling, and surface engineering. 